\title{
Judiciário e interpretação: entre Direito e Política
}

\section{Judiciary and interpretation: between law and politics}

\author{
Alexandre Araújo Costa*
}

\section{Resumo}

Este artigo trata das conexões entre a estrutura do sistema político, a organização do Poder Judiciário e os modos de interpretação da lei. O texto inicia analisando as relações existentes entre Política, Direito e Judiciário, ressaltando o papel inerentemente político do Poder Judiciário. Em um segundo momento, o artigo traça um panorama histórico de como a evolução do Direito envolveu modificações constantes nos critérios hermenêuticos, mostrando que a atividade interpretativa tem uma dimensão política na medida em que permite alterações que contribuam para a adaptação de um grupo social ao seu ambiente. Por fim, o artigo ressalta algumas das características principais da estrutura contemporânea do Direito e mostra como esses elementos (especialmente a universalização do Direito legislado, a universalização da jurisdição, o controle de constitucionalidade e o estabelecimento de direitos sociais) contribuem para determinar a estrutura judicial contemporânea e a hermenêutica que orienta os discursos de aplicação no campo do Direito.

Palavras-chave: Poder Judiciário. Interpretação. Hermenêutica. Direito. Política.

\section{Abstract}

This article addresses the connections between the structure of the political system, the organization of the judiciary and the ways of interpreting the law. The text begins by analyzing the relationship between politics, law and judiciary and emphasizing the inherently political role of the judiciary. In a second

Doutor e mestre em direito pela UnB. Professor do Instituto de Ciência Política (IPol) da UnB e dos programas de pós-graduação em Ciência Política e em Direito. Coordenador do Grupo de Pesquisa em Política e Direito. Brasília - DF - Brasil. Email: alexandre.araujo.costa@gmail.com 
step, the article provides a historical overview of how the evolution of the law involved constant changes in the hermeneutical criteria, showing that the activity of interpretation has a political dimension to the extent the law allows the introduction of changes that contribute to the adaptation of a group their social environment. Finally, the article highlights some of the main features of the contemporary structure of law and shows how these elements (especially the universalization of statutory law, the universal jurisdiction, judicial review and the establishment of social rights) contribute to determining the contemporary judicial structure and the hermeneutics that guides discourses of application in the field of the law.

Keywords: Judiciary power. Interpretation. Hermeneutics. Law. Politics.

\section{Introdução}

Que relações existem entre esses três elementos? O senso comum tende a responder que o Judiciário é uma instituição cuja finalidade é aplicar o Direito elaborado pela Política. Nesse contexto, o Judiciário seria uma organização burocrática; o Direito, um conjunto de regras; e a Política, uma atividade que envolve a tomada de decisões em nome da coletividade. Tal perspectiva parece respeitar a tripartição dos poderes preconizada por Montesquieu, de tal forma que o Legislativo crie as leis, o Executivo governe com base nelas e o Judiciário as aplique aos casos concretos. Nessa visão, os poderes Executivo e Legislativo aparecem com uma forte dimensão política, enquanto o Judiciário deveria ser politicamente neutro, para que fosse capaz de aplicar o Direito de maneira técnica e imparcial.

Esse tipo de concepção está na base do diagnóstico de que, hoje, vivemos uma judicialização da Política, caracterizada por uma invasão judiciária de territórios que deveriam ser ocupados pelo Legislativo e pelo Executivo. No sentido original traçado por Vallinder (1994, p. 91), esse processo foi identificado, fundamentalmente, com o incremento do ativismo por parte da magistratura, mas a utilização recorrente e imprecisa da categoria judicialização fez com que os seus contornos se 
diluíssem, resultando em uma fluidez conceitual que foi bem delineada por Maciel e Koerner (2002, p. 114) há mais de uma década.

Torna-se cada vez mais comum a percepção de que o Judiciário tem ultrapassado as fronteiras de sua autoridade constitucional, porque, em vez de ser um mero intérprete, ele tem elaborado normas sob o pretexto de aplicá-las. Esse diagnóstico está cada vez mais presente no próprio discurso legislativo, tendo inspirado a apresentação da PEC n. 33/2011, que se volta a ampliar o quórum para decisões judiciais de inconstitucionalidade, condiciona o efeito vinculante de súmulas à sua aprovação pelo Congresso Nacional e impede o controle judicial da constitucionalidade de Emendas à Constituição. Na justificação dessa proposição, o deputado Nazareno Fonteles (2011) afirma que "o STF deixou de ser um legislador negativo, e passou a ser um legislador positivo. E diga-se, sem legitimidade eleitoral. O certo é que o Supremo vem se tornando um superlegislativo". Além disso, o deputado subscreve a tese de Alfredo da Silva (2010), no sentido de que o ativismo judicial "se resume num comportamento cometido pelo poder judicante ofensivo ao princípio democrático, mas retoricamente preocupado com a efetividade do princípio da supremacia constitucional".

Mas será correto esse diagnóstico? O presente artigo sustenta que tal visão é incorreta, por ser baseada em uma "concepção equivocada do Poder Legislativo e uma concepção estreita de democracia" (FREEMAN, 1994, p. 198), ligada a uma compreensão formal das relações entre os poderes, implicando em um sistema de divisão de poderes idealizado e muito distante da efetiva organização do Estado brasileiro contemporâneo (MACIEL; KOERNER, 2002, 1998, p. 129). Além disso, esse diagnóstico normalmente envolve a ideia de que o Judiciário deveria se limitar a aplicar as leis segundo técnicas racionais de interpretação, evitando o ativismo que o faz ir "além do que o caso concreto exige, criando normas que não passaram pelo escrutínio do legislador" (FONTELES, 2011).

Embora seja forçoso admitir que o Judiciário não se limita a uma atuação meramente reveladora de sentidos implícitos nos textos, tal reconhecimento não permite concluir que o ativismo judicial representa 
uma distorção contemporânea da atividade judicial, nem que as decisões ativistas "representam grave violação ao regime democrático e aos princípios constitucionais e aos princípios constitucionais da soberania popular e da separação de poderes" (FONTELES, 2011).

Não existe novidade alguma na defesa de que não se pode exigir dos magistrados uma postura politicamente neutra, porque o Judiciário é uma instituição cuja função é realizar uma atividade política de importância fundamental: a aplicação do Direito, que não é uma função científica, muito embora o discurso judicial faça um grande esforço para se qualificar como tal. Tal posição está no centro do debate jurídico, ao menos desde que a Teoria Pura do Direito de Kelsen (2003, p. 394) reconheceu expressamente o caráter político da atividade judicante ao afirmar que "a interpretação feita pelo órgão aplicador do Direito é sempre autêntica", no sentido de que ela envolve a criação de normas.

Essa posição se contrapunha à hermenêutica tradicional, que acreditava ser lícito esperar da atividade judicial a determinação da solução jurídica correta para todos os casos juridicamente relevantes (KELSEN, 2003, p. 391). A crítica de Kelsen à hermenêutica tradicional mantém a sua relevância justamente porque a dogmática jurídica continua se apresentando como uma disciplina capaz de extrair da legislação soluções juridicamente corretas, mediante processos racionais de interpretação normativa. Além disso, não podemos perder de vista que Kelsen também se opunha às correntes de matriz sociológico que buscavam construir uma metodologia científica para a identificação do Direito nos fatos sociais e históricos através de uma "exegese atualizadora, com as novas exigências, necessidades e transformações resultantes dos processos sociais, econômicos e políticos que caracterizam, em seus múltiplos e complexos aspectos, a sociedade contemporânea" (BRASIL. STF, HC n. 96.772). Esse trecho da ementa formulada pelo ministro Celso de Mello no habeas corpus que decidiu pela inconstitucionalidade da prisão do depositário infiel bem poderia ter sido escrito por François Gény ou Eugen Ehrlich, que defenderam modos de interpretação capazes de adaptar o Direito às realidades sociais mutantes (COSTA, 2008). 
Existe, porém, uma grande diferença entre as posições da jurisprudência sociológica do final do século XIX e da jurisprudência principiológica do final do século $\mathrm{XX}$, normalmente identificada como neoconstitucionalismo (SARMENTO, 2009), as quais tendem a sustentar que as questões envolvendo interesses devem ser resolvidas por processos políticos que manifestem a vontade majoritária, mas que "questões de princípio devem ser decididas, em última instância, por cortes constitucionais, com base em argumentos de razão pública" (BARROSO, 2010, p. 17), ligadas à concretização hermenêutica dos princípios constitucionais. Essa concepção tende a reconhecer o princípio de que a magistratura está vinculada às normas constitucionais, e não aos valores sociais majoritários, o que conduz à elaboração de um discurso hermenêutico idealista, baseado na ideia de que o Direito contém soluções para todos os casos, inclusive para os mais difíceis, e que os magistrados devem resolver esses casos por meio de uma interpretação cuidadosa e uma articulação criteriosa dos princípios constitucionais.

Já a jurisprudência sociológica percebia que os argumentos baseados estritamente nas leis e em sua interpretação eram insuficientes para organizar a resolução dos conflitos sociais da época, por isso, em vez de apontar para a noção idealista de que todas as soluções deveriam ser buscadas dentro do Direito, indicaram que era preciso torná-lo permeável aos valores sociais majoritários. Ela era cética quanto à possibilidade de o Direito se esgotar na lei e de resolver as controvérsias jurídicas tomando como base única as normas legisladas (inclusive as constitucionais), reivindicando a possibilidade de uma investigação científica capaz de revelar o Direito presente nas relações sociais (EHRLICH, 1986, p. 14). Essa investigação se afirmava livre por não estar circunscrita somente às normas positivadas pelo Estado e também se declarava "científica, porque ela não pode encontrar bases sólidas senão nos elementos objetivos que somente a ciência lhe pode revelar" (GÉNY, 1954, p. 78).

Os juristas ligados a essa corrente estavam vinculados a uma abertura do Direito aos valores sociais majoritários, especialmente nos 
casos em que o Direito positivo se revelasse insuficiente para orientar a tomada de decisões judiciais. Mas eram enfáticos ao dizer que essa operação deveria ser cuidadosa, sendo necessárias precauções para evitar o arbítrio interpretativo dos juízes, representado, no imaginário da época, pela jurisprudência sentimental do bom juiz Magnaud (PERELMAN, 1998, p. 96). Holmes e Gény foram especialmente enfáticos ao afirmarem que a criatividade judicial somente poderia ser exercida nos espaços de lacuna, sendo célebre a declaração de Wendell Holmes: "I recognize without hesitation that judges do and must legislate, but they can do so only interstitially" (HOLMES apud TAMANAHA, 1997, p. 204).

A autoridade judicial somente se libertava dos textos definidos pela autoridade legislativa nos casos em que fosse possível a caracterização de uma lacuna, pois não parecia compatível com um sistema democrático que os juízes substituíssem os legisladores nas decisões políticas do Estado. Com o tempo, surgiram teorias que defenderam uma liberdade judicial cada vez maior, ligadas a uma hermenêutica que não apontava para os valores sociais predominantes, mas para uma atividade interpretativa voltada a identificar os valores implícitos no próprio sistema do Direito positivo. Karl Larenz narra meticulosamente essa virada para uma jurisprudência dos valores, que, em vez de buscar fora do Direito os elementos valorativos capazes de complementar as regras positivadas, passou a justificar o ativismo judicial por meio de uma hermenêutica voltada a identificar os valores subjacentes ao próprio ordenamento (LARENZ, 1982, p. 143). Olhando em perspectiva, não é demasiado lembrar que tais perspectivas estiveram ligadas à prática jurídica de regimes totalitários, pois a jurisprudência nazista não era baseada no positivismo que exigia o cumprimento da lei, mas em teorias que, como as do próprio Larenz, apregoavam maior independência judicial, proclamando "a importância de princípios orientados por valores e teleologias" (NEVES, 2012).

Já no debate constitucional contemporâneo, avolumam-se afirmações que contribuem para a democracia identificar tensões valorativas, como colisões de princípios que podem ser solucionadas 
a partir da aplicação de métodos jurídicos de interpretação, e não de métodos políticos de tomada de decisão. Na base dessa defesa, precisa haver uma teoria interpretativa que defenda a possibilidade de que problemas desse tipo podem ser resolvidos adequadamente mediante a aplicação de procedimentos interpretativos. Portanto, não deve causar espanto o fato de serem constantes as críticas às posições que acentuam o caráter indeterminado do Direito, parecendo mais comuns as defesas da tese de Dworkin (2003, p. 305) acerca da existência de uma solução correta do que das teses de Hart (1996, p. 335) sobre o caráter lacunar do Direito. Em especial, há uma valorização do neoconstitucionalismo, que tem conquistado espaços cada vez mais relevantes, especialmente no discurso dos magistrados, ao defender um incremento na autoridade judicial para julgar em nome de princípios e não de regras.

Não obstante vários juristas apontarem o aspecto legislativo da atividade judicial, é raro que os próprios magistrados afirmem tal fato em suas decisões, sendo mais comum a adoção de um discurso que indica se tratar de um processo no qual se revela o sentido correto da norma. Como reconhece Luis Roberto Barroso (2010, p. 15), o discurso judiciário padrão indica que "juízes são independentes da política e limitam-se a aplicar o direito vigente, de acordo com critérios aceitos pela comunidade jurídica". Por isso mesmo merece atenção o fato de que alguns magistrados têm adotado um reconhecimento explícito de suas funções legislativas, como é o caso das afirmações de Celso de Mello na ementa do HC n. 96.772, declarando que a interpretação judicial é um "instrumento juridicamente idôneo de mudança informal da Constituição" (BRASIL. STF, HC n. 96.772), e, principalmente, na ementa do MS 26.603:

O exercício da jurisdição constitucional, que tem por objetivo preservar a supremacia da Constituição, põe em evidência a dimensão essencialmente política em que se projeta a atividade institucional do Supremo Tribunal Federal, pois, no processo de indagação constitucional, assenta-se a magna prerrogativa de decidir, em última análise, sobre a própria substância do poder. (STF, MS n. 26.603) 
Essa afirmação ultrapassa em muito a citada frase de Oliver Wendell Holmes, que restringe a atividade criativa do Judiciário ao preenchimento de lacunas. A categoria de lacuna, que, durante muitas décadas, organizou o exercício do ativismo judicial, ficou limitada a um uso bem mais restrito, pois o discurso do ativismo judicial passou a ser baseado na necessidade de efetivar princípios presentes no Direito, e não de corrigir as ausências. Assim, em vez de uma categoria de uso restrito a situações atípicas, os juristas passaram a manejar categorias que converteram a exceção na regra. Em todos os casos, é preciso avaliar a influência dos princípios constitucionais e retirar deles consequências normativas, mesmo quando se trata de princípios implícitos, como o da proporcionalidade ou razoabilidade.

Neves (2012) aponta que essa ampliação do uso jurisprudencial de argumentos principiológicos conduziu a uma trivialização e a uma correspondente inconsistência no tratamento dos princípios constitucionais por parte do STF.

Tal situação de confusão jurisprudencial relaciona-se com o fascínio doutrinário, que se expressa no lugar comum do chamado 'neoconstitucionalismo', ao relacionar os princípios com a democracia e as regras com a postura autoritária.

O juiz não pode alterar o texto da lei, mas é demasiadamente ingênua a noção de que norma é texto. Nas leis, o que nos obriga não é o significante, mas o significado que damos a ele. É claro que o significado precisa estar bem articulado com o texto, mas não há como determinar o sentido de uma regra sem avaliar adequadamente os seus contextos de elaboração e aplicação. Porém, não é de todo incomum que a interpretação judicial se descole tanto do texto e do contexto em que foi legislado a ponto de muitos colocarem em dúvida o próprio caráter aplicativo da atividade judicial.

A atividade hermenêutica dos magistrados, mediante a qual se confere sentido a um texto, permite que o Direito seja modificado sem que seja necessário modificar o texto das normas. No campo constitucional, 
que tem a peculiaridade de lidar com textos cuja alteração é dificultada pelas autoridades políticas, esse fenômeno chegou a merecer uma denominação própria desde o início do século $X X$, e que está em voga na dogmática brasileira contemporânea: mutação constitucional. Essa categoria jurídica, delineada inicialmente por Jellinek e desenvolvida por Hsu Dau-Lin, opõe-se à noção de reforma constitucional, que alteraria direta e intencionalmente os textos das constituições (CARVALHO, 2011, p. 9614). Quando as alterações hermenêuticas são compatibilizáveis com os textos, o discurso jurídico tipicamente as descreve como um processo de câmbio interpretativo, em que um entendimento se sobrepõe a outro. Somente quando esse trânsito ultrapassa o sentido literal possível (LARENZ, 1982, p.414) é que se apela ao conceito de mutação constitucional, por meio do qual se opera "não a atribuição de uma (nova) norma a um texto (Sinngebung), mas, sim, a substituição de um texto por outro texto" (STRECK; CATTONI; LIMA, 2007).

Um movimento desse tipo se anuncia, por exemplo, no julgamento, ainda em curso, da Reclamação n. 4.335, em que ministros do STF defendem a possibilidade de uma decisão da Corte aumentar o seu próprio poder, estabelecendo jurisprudencialmente a equiparação entre os efeitos das decisões em controle abstrato e em controle difuso de constitucionalidade, mediante uma interpretação que anula a exigência explícita da Constituição de que apenas o Senado pode conferir efeitos erga omnes a decisões do STF em sede de controle difuso (STRECK; CATTONI; LIMA, 2007). A defesa mais extensiva dessa posição, tanto no campo judicial como no teórico, foi feita pelo ministro Gilmar Mendes (2004, p. 166), que indicou a ocorrência de uma mudança de interpretação do STF acerca do papel do Senado, de tal modo que "valendo-nos dos subsídios da doutrina constitucional a propósito da mutação constitucional, poder-se-ia cogitar aqui de uma autêntica reforma da Constituição sem expressa modificação do texto".

É bastante recente essa utilização da categoria de mutação constitucional para designar (e legitimar) a possibilidade de órgãos judiciários alterarem radicalmente o sentido das normas constitucionais para adaptá-las às concepções políticas dominantes nos tribunais. $E$ 
é mais recente ainda essa admissão da possibilidade de um tribunal alterar explicitamente, por via interpretativa, os limites da própria competência. Além disso, é crescente o número de julgamentos em que a atuação judicial ultrapassa o sentido literal possível das normas, dando margem a uma atuação judicial de caráter eminentemente criativo. Nesses casos, mesmo juristas que entendem que o conjunto dos entendimentos semanticamente viáveis constitui uma espécie de moldura a determinar os limites da atividade interpretativa propriamente dita, eles podem ser conduzidos a esclarecer, seguindo o exemplo de Kelsen, que nada obriga um juiz a decidir dentro do campo da moldura. Para Kelsen (2003, p. 394), o esclarecimento da moldura era um papel da ciência do Direito, mas era impossível exercer a atividade judicante sem fazer escolhas políticas, as quais, inclusive, poderiam conduzir a uma decisão fora desses limites semânticos.

Cabe ressaltar que a dicotomia legada pela Teoria Pura do Direito não é entre Direito e Política, mas entre Direito e Ciência. Existe, para Kelsen, uma Ciência do Direito e uma Política do Direito, mas a atividade judicial, evidentemente, integraria a Política, na medida em que implica na realização de juízos valorativos. $E$ as tentativas de revestir a Política como uma forma de ciência foram apontadas por ele como uma busca ideológica de dar sustentação pseudocientífica a determinadas escolhas políticas.

Não obstante as críticas que o ativismo judicial do STF tem recebido, especialmente quando se volta a restringir a competência constitucional do Poder Legislativo (CARVALHO, 2011; STRECK; CATTONI; LIMA, 2007), devemos reconhecer que essa atividade hermenêutica criadora, capaz de alterar radicalmente o sentido das normas sob o pretexto de concretizá-las, tem uma origem muito mais antiga e uma amplitude maior do que esse debate deixa entrever. Enquanto o Direito não era primordialmente legislado, cabia à atividade interpretativa reconstruir, a cada momento, as normas consuetudinárias que eram aplicadas pelos julgadores. Dizer o Direito era, também, formular as próprias regras extraídas do convívio social, reinterpretando os costumes. E é cabível recordar que a atividade interpretativa precede historicamente a própria 
função legislativa, na medida em que a necessidade de interpretar e aplicar as leis costumeiras é anterior ao próprio desenvolvimento de instituições políticas com autoridade para legislar.

Na escala evolutiva do homo sapiens, podemos afirmar que o juiz antecede o legislador, e o reconhecimento dessa precedência esclarece alguns pontos relevantes para a compreensão das relações entre Política e Judiciário. Tal percepção também nos permite traçar paralelos que iluminam a relação entre Direito e Política, na medida em que esses elementos se desenvolvem de forma entrelaçada nas sociedades humanas. Essa visão histórica, porém, é, muitas vezes, deixada de lado pelos juristas, especialmente porque as preocupações que os movem são pouco afeitas ao historicismo. Mais comum é uma visão platônica, que cinde a realidade em duas partes: um mundo sensível, em que as regras positivas são elaboradas, e um mundo inteligível, habitado por conceitos, estruturas e princípios de validade universal. Seguindo a tradição grega, os filósofos do Direito, normalmente, dão preponderância a esse plano inteligível, no qual pairam eternamente entidades sem história. E seguindo a tradição moderna, os dogmáticos buscam revelar o sentido correto da lei, numa atividade que nega a própria historicidade, porque se concentra apenas no tempo presente.

Todavia, uma compreensão evolutiva da estrutura do Direito nos possibilita compreender melhor as funções atuais do Poder Judiciário, na medida em que a sua organização é dependente da forma que as normas jurídicas assumem em cada cultura. Tanto na filosofia quanto na prática, o historicismo não encontra um solo fértil. E por isso mesmo é que se torna relevante assumir a perspectiva genealógica proposta por Nietzsche, para quem tudo o que é humano precisa ser estudado como história.

Adotando essa perspectiva, o presente texto se volta para contribuir com a compreensão de que a judicialização da Política é apenas um novo nome para o velho fenômeno de que as normas imutáveis são modificadas constantemente pelos intérpretes. Não há nada de novo no fato de que a interpretação é a forma pela qual modificamos as normas 
jurídicas impostas por uma autoridade superior, seja ela a autoridade da tradição, de deus, do rei, do povo ou do poder constituinte. E quando o Direito passou a ser fixado em fórmulas escritas, os aplicadores da lei logo viram necessidade de seguir o exemplo dos hermeneutas religiosos que lidavam com livros sagrados: era preciso adaptar o Direito por meio de interpretações que alterassem as normas sem modificar os textos.

Tampouco há inovação no fato de os intérpretes adotarem uma retórica que negue o fato de a interpretação ser uma atividade política, envolvendo uma escolha constante entre modificar ou manter as estruturas sociais. Não foi Montesquieu nem o liberalismo iluminista que inventou a estratégia de apresentar os intérpretes como as bocas que falam em nome da lei. Se algo de novo existe nesse campo é a busca contemporânea de desenvolver um discurso político-interpretativo que articule, explícita e criticamente, esses pressupostos. E este artigo pretende contribuir para o debate acerca da legitimidade do controle judicial de constitucionalidade a partir do desenvolvimento de uma compreensão histórica das relações entre as estruturas jurídicas e as teorias da interpretação.

\section{Evolução do Direito e da atividade interpretativa}

As aulas de introdução ao Direito costumam partir da afirmação de que ubi societas ibi jus, ou seja, onde há sociedade, há Direito. Essa, contudo, é uma afirmação falsa, pois não leva devidamente em conta que a própria humanidade surge de um processo de evolução. A sociedade precede o Direito, na medida em que existem várias organizações sociais cuja estrutura antecede o homo sapiens e não envolve a noção de dever. A organização de uma colmeia, por exemplo, envolve uma série de ações coordenadas, mas não existe, em tais sociedades, nenhum tipo de obrigação.

Obrigação é uma categoria humana que nasce da nossa vida em sociedade e se relaciona com a possibilidade de coordenar as condutas dos indivíduos a partir do sentimento de dever. Esse sentimento não é uma simples emoção, como o nojo ou a tristeza. Trata-se de uma 
elaboração simbólica que parte dessas emoções e é capaz de gerar uma reação de indignação moral frente a certas situações, especialmente frente ao sofrimento e à desigualdade. Nós podemos ser condicionados a reagir com indignação a certas situações concretas, especialmente porque aprendemos isso mediante a imitação do comportamento de outros membros da sociedade. Esse tipo de reação pode ser observado em outros mamíferos, como chimpanzés (YAMAMOTO; HUMLE; TANAKA, 2013).

Todavia, existe uma capacidade humana peculiar que permite condicionar as pessoas a sentirem indignação moral com condutas que elas nunca observaram: é a nossa capacidade de linguagem abstrata. As nossas sociedades desenvolveram a categoria "proibido" para designar uma série de fatos cujo único ponto em comum é o fato de que eles causam indignação: torturar, tratar pessoas desigualmente, cumprir certos rituais. Essa noção abstrata permite modelar a nossa capacidade de indignação de uma forma muito elástica, pois essa emoção pode aflorar pelo fato de que nos deparamos com um ato que havia sido designado como proibido.

Essa possibilidade de designar linguisticamente certas situações abstratas permite que as comunidades humanas alterem, de modo radical, suas formas de organização. O desenvolvimento dessa comunicação por meio de conceitos abstratos (ou seja, linguagem) ocorreu dentro de um processo evolutivo o qual não cabe descrever aqui, mas que teve lugar especialmente nos últimos milênios. Arbib sustenta que "the first homo sapiens were language-ready but did not have language in the modern sense", o que envolveu uma "change from action-object frames to verb-argument structures to syntax and semantics", que ocorreu há cerca de 100.000 anos (ARBIB, 2005, p. 118). Esse aflorar da linguagem possibilitou aos seres humanos coordenar os seus comportamentos segundo uma gama muito diferenciada de padrões, o que permitiu às sociedades humanas assumir formas muito diversas de organização.

O desenvolvimento humano de uma linguagem capaz de fazer qualificações morais tornou possível que nós interpretássemos as 
nossas relações sociais em termos de dever. Em algum momento da evolução da linguagem, tornamo-nos capazes de interpretar certos atos não apenas como desejáveis, mas como obrigatórios, pois a existência de uma normatividade social envolve a possibilidade de declarar linguisticamente que alguns atos são objetivamente devidos. Esse foi o começo do discurso normativo que está no núcleo de estruturas sociais como a religião, a moralidade e o Direito.

O fato de que as sociedades humanas tratam uma vasta gama de condutas como proibidas ou obrigatórias (e esses dois conceitos somente existem na nossa linguagem abstrata) permite que essas comunidades assumam e reproduzam as mais diversas formas de organização. E o fato de os seres humanos poderem aprender muita coisa a partir do simples manejo da linguagem permite uma acumulação cultural imensa, na medida em que os comportamentos aprendidos por um indivíduo podem ser transmitidos para outras pessoas e gerações, o que possibilita que certos arranjos culturalmente determinados permaneçam estáveis por longos períodos de tempo.

Essa possibilidade de adotar diversas configurações é o que chamamos de complexidade, e a nossa capacidade linguística permite organizações sociais mais complexas que as dos outros animais. Complexidade, contudo, é sempre uma faca de dois gumes. O aumento dela incrementa a nossa capacidade de variação, o que possibilita ao homo sapiens se adaptar aos mais diversos ambientes. Porém, as mudanças que ocorrem em uma sociedade nem sempre são adaptativas, pois elas não aumentam necessariamente nossa capacidade de sobreviver em nosso ambiente. A possibilidade de fazer coisas muito diversas implica a possibilidade de cometer erros novos e fatais. Por exemplo, quanto maior o nosso domínio sobre a natureza, maiores são os riscos que corremos de nos extinguirmos em virtude do nosso comportamento.

Uma ampla capacidade de aprendizado (ou seja, de adquirir novos padrões de comportamento) poderia ter conduzido nossa espécie à extinção, caso não houvesse mecanismos que evitassem 
comportamentos destrutivos. Assim, não deve causar espanto o fato de que as sociedades humanas que sobreviveram aos últimos 100 mil anos tenham vivido um aumento de complexidade social e um desenvolvimento de formas capazes de selecionar variações comportamentais, de modo a manter um equilíbrio entre mutação e permanência. Os comportamentos possíveis são muitos, mas há vários mecanismos sociais que estimulam certas condutas e desestimulam outras, equilibrando variação e estabilidade.

Um dos mecanismos mais relevantes é a fixação consuetudinária de padrões normativos de comportamento. Uma série de condutas é vedada ou estimulada por meio de noções deônticas, como proibição e dever. Com isso, nossas sociedades são capazes de perpetuar seus padrões de comportamento mediante a instituição de leis que prescrevem deveres ou proíbem certos atos, e que são sentidas como obrigatórias.

Em sociedades humanas mais simples, uma noção genérica de lei poderia ser suficiente para organizar a comunidade. Proibição de comer certos alimentos, prescrição de realizar alguns ritos funerais, vedação do incesto, tudo isso pode ser regulado com uma percepção genérica de que certos comportamentos estão de acordo com a lei e que outros a contrariam. Todavia, quanto mais complexa a sociedade, maior tende a ser a dúvida gerada pela aplicação da lei, especialmente porque as sociedades complexas se veem constantemente frente a situações novas. Como manter a estabilidade social repetindo os padrões definidos na lei quando as situações novas não são reguladas diretamente por ela? As leis consuetudinárias não formam sistemas completos, mas conjuntos cheios de lacunas que regem apenas as situações conhecidas de acordo com critérios estratificados na tradição.

Como resolver casos em que somente parte da comunidade reage com indignação? Como podemos aplicar a velha lei a situações novas ou a casos que fogem do padrão? Essa necessidade de enfrentar novos problemas a partir das estruturas simbólicas existentes na sociedade faz com que a interpretação da lei seja um velho problema da humanidade. 
Além disso, nossa sobrevivência sempre dependeu tanto da capacidade de manter as estruturas sociais quanto da nossa capacidade de modificálas. Os grupos humanos sempre enfrentaram contextos mutantes, de forma que a sobrevivência às mudanças ambientais e internas exige uma possibilidade de variação na própria lei.

Essa possibilidade de mutação, contudo, não significava, originalmente, que a lei podia ser modificada pelas pessoas que exerciam um papel de liderança. A criação de mecanismos de alteração da lei por parte dos governantes aparece em um momento bastante posterior da nossa evolução. Enquanto não houve centralização da autoridade política, tampouco houve instituições legislativas; mas isso não significava que a lei fosse imutável. Isso porque uma lei pode variar na medida em que mudam as percepções sociais sobre ela; em que se modifica o sentimento dominante de obrigação. Mas a alteração consuetudinária da norma envolve longos tempos, em que o padrão dominante de avaliação varia lentamente. Existe, porém, um mecanismo sutil de mudança: a mutação por via interpretativa.

$\mathrm{Na}$ medida em que a aplicação das leis a contextos duvidosos é mediada por algumas autoridades, estas podem alterar o sentido da norma a partir de uma redefinição de suas consequências para os casos concretos. A intervenção da autoridade interpretativa permite uma mudança que não precisa esperar o câmbio gradual da percepção social da norma. Essa interpretação criativa das leis permite aumentar a capacidade de variação da organização social, embora os procedimentos interpretativos tendam a admitir somente mutações discretas, que sejam percebidas socialmente como realização do Direito e não como sua alteração.

Essa atividade interpretativo-aplicativa é realizada por todos os órgãos políticos, mas, no Poder Judiciário, ela ocupa uma posição de maior destaque. Por meio dela, cada juiz reinterpreta as normas que aplica, o que lhe confere uma relevância na definição dos direitos e obrigações dos cidadãos. Ao tratar das leis, os intérpretes terminam por determiná-las, redefinindo os seus contornos, sentidos, fontes, consequências: tudo isso integra a atividade hermenêutica. Tal estratégia 
tornou possível que alterássemos a lei na medida em que buscávamos compreendê-la, o que resultou numa combinação de estabilidade social com a possibilidade de incorporar variações discretas.

\section{Interpretação, revelação e variação do Direito}

Como dizia Hobbes (1997, p. 213), em meados do século XVII, "todas as leis, escritas ou não, têm necessidade de uma interpretação". Toda lei precisa de intérpretes para que seja aplicada, e toda atividade interpretativa implica uma constante ressignificação da lei, dado que o hermeneuta sempre exerce sua função a partir de seu lugar na história e na cultura. Como os ambientes naturais e culturais estão em permanente modificação, a sensibilidade das pessoas e as interpretações que elas realizam também estão sujeitas a uma alteração constante.

Normalmente, essas alterações são discretas, de modo que as implicações de cada uma delas não se apresentam como ruptura, e sim como continuidade. A interpretação ocorre dentro de um discurso de realização do Direito e mesmo quando essa interpretação se afasta do sentido literal das regras, isso é feito sob o argumento de que o sentido correto da norma não está em sua literalidade, mas em outro lugar: na vontade do legislador, na mens legis, no sentido sistemático, nos princípios gerais do Direito ou em qualquer dos outros lugares onde costumamos assentar um significado que se choca com a letra. Dessa forma, ainda que os sentidos de uma norma sofram uma clara renovação, como ocorreu no recente julgado do STF sobre união homoafetiva (ADI n. 4277 e ADPF n. 132), o discurso interpretativo apresenta essa alteração no Direito como uma revelação do Direito.

Revelação é uma palavra importante porque acentua a origem religiosa da hermenêutica, que, originalmente, estava ligada com a interpretação de leis com uma dimensão sagrada. Quando um profeta revela uma norma, ele não se coloca na função de criador, mas apenas de intérprete privilegiado, capaz de ter acesso a uma verdade que não se mostra para as outras pessoas. De modo semelhante, quando uma pessoa interpreta uma norma, apenas revela o sentido do texto, 
entendendo que não cabe a ela criar direitos e obrigações, mas esclarecê-los.

No âmbito das leis religiosas, especialmente nas religiões ligadas a livros sagrados, os intérpretes não podem alterar o texto, o qual precisa ser tratado com um cuidado reverencial. Extrair um sentido adequado de um livro imutável é uma velha tarefa da hermenêutica religiosa (COSTA, 2008). Nesse contexto, a atividade do intérprete é dissipar as dúvidas interpretativas, desvelando o sentido correto dos textos. Por isso mesmo, o bom intérprete precisa lidar com uma sutil dialética da obscuridade, mostrando que certos pontos, aparentemente claros, são verdadeiramente obscuros, para poder esclarecê-los com a sua arte. 0 intérprete define a lacuna que ele supre, as antinomias que resolve e as obscuridades que esclarece.

Essa atividade é capaz de introduzir mudanças discretas no sentido das leis. Essas mudanças são apresentadas como uma realização da própria lei, porém, acumuladas ao longo do tempo, podem gerar mutações significativas no Direito. O texto da Bíblia não mudou em vários séculos, mas a sua interpretação variou radicalmente. O texto da Constituição dos EUA é basicamente o mesmo há 200 anos, embora a atividade interpretativa dos juízes o tenha modificado radicalmente. O mesmo se diz do Código Civil de 1916, em suas muitas décadas de vigência, e mesmo da atual Constituição Federal, que, nas suas poucas décadas de vida, já sofreu mudanças hermenêuticas evidentes, como no caso do mandado de injunção (v. Mandados de Injunção n. 107 e n. 670) e da união homoafetiva.

Embora essa relevância política da atividade interpretativa não tenha sido uma invenção do século $X X$, foi nele que a interpretação judicial ganhou especial relevância e se consolidou mundialmente a autoridade das Cortes para interpretar diretamente o texto constitucional e fazer julgamentos com efeitos erga omnes. Se os juízes pudessem interpretar apenas as leis, eles não teriam como afastar a aplicabilidade da legislação com base em argumentos constitucionais. Porém, estabelecida a competência dos juízes para julgar diretamente com 
base na constituição, como afirmar que eles ultrapassam os limites de sua competência?

Os juízes sempre interpretarão as normas que compõem o Direito válido em seu tempo. Houve momentos em que esse Direito tinha uma dimensão religiosa e era composto basicamente por costumes; houve momentos em que a solução dos casos deveria ser baseada em uma reinterpretação do Direito Civil romano. Estamos em uma época na qual o Direito legislado ganhou ampla relevância e as normas da legislação constitucional e infraconstitucional abrangem cada vez mais aspectos da nossa vida.

Some-se a isso o fato de que os nossos ordenamentos jurídicos são cada vez mais repletos de normas principiológicas, pautas abertas, promessas políticas genéricas e uma série de estruturas normativas altamente abstratas, que somente podem ser aplicadas a casos concretos mediante uma atividade hermenêutica concretizadora altamente criativa. A estrutura do Direito contemporâneo, bem como a sua amplitude, exige dos juízes uma postura muito mais ativa do que se exigia de um magistrado no século XVIII ou XIX. Isso indica que o diagnóstico de uma judicialização da Política, vista como um desvio no comportamento dos juízes, talvez tenha bases menos sólidas do que possa parecer.

Quando o Direito muda, também se alteram a função dos intérpretes, os instrumentos que eles podem utilizar e os cânones hermenêuticos que guiam a sua atividade. A introdução de mudanças no Direito é uma das atividades mais típicas da Política, estando ligada ao que identificamos como função legislativa. Mas também é uma atividade típica dos juízes a alteração paulatina das normas, mediante processos de reinterpretação. Nessa medida, devemos ter em mente que o juiz sempre foi um ator político.

Isso não significa que a magistratura possa, a cada momento, revolucionar o Direito, visto que a atividade interpretativa normalmente admite apenas mudanças discretas, sob pena de ser entendida como criação e não interpretação. Mas é claro que o limite entre esses 
polos é composto por uma grande zona cinzenta, pois toda atividade hermenêutica é dependente do texto e do contexto, mas, ao mesmo tempo, também envolve uma dose de criatividade. Qual é a dose adequada ao Judiciário atual?

Essa me parece ser a pergunta mais adequada para enfrentar o debate contemporâneo. Com ela, evitamos a mistificação de que é preciso criar um método racional e científico que impeça a criação judicial. Mas também evitamos a mistificação oposta, no sentido de que a ausência de um método impessoal geraria um campo de discricionariedade em que os juízes poderiam decidir da maneira como lhes aprouvesse.

Se a função dos juízes é política, ela é estabelecida politicamente, a partir de composições de interesses realizadas no interior da sociedade. Existem limites políticos para a atuação judicial, mesmo que eles não possam ser identificados de forma imediata, com limites jurídicos. O STF tem a função de guardar a Constituição, mas isso não quer dizer que ele tenha completa liberdade para atribuir sentidos ao texto constitucional. No campo estritamente formal, não há limites jurídicos para a sua autoridade de interpretação. Todavia, no campo dos fatos e das interações políticas, há várias limitações ao poder do STF, porque sua efetiva capacidade de influenciar a política é baseada na percepção social da sua legitimidade, que precisa ser reafirmada e reconquistada a cada julgamento.

De fato, assistimos a um momento de expansão da importância da atuação judicial na fixação do Direito. Decisões políticas de caráter cada vez mais polêmico são decididas por meio do discurso judicial de interpretação. Mas esse trânsito é mais bem compreendido como um incremento no protagonismo político do Poder Judiciário ou como uma judicialização indevida da Política?

\section{Universalização do Direito legislado}

Para dimensionar se os juízes estão ou não ultrapassando os limites de seu poder, é importante não mistificarmos a função do Poder 
Legislativo. Precisamos ter em mente que a função dos legisladores foi mais alterada pelos Estados de Direito e pelo constitucionalismo do que a própria função dos juízes. Estamos tão acostumados a pensar nos legisladores como os produtores das regras que regulam os vários âmbitos da vida social que, muitas vezes, esquecemo-nos de que essa é uma função bastante nova, que remonta ao projeto iluminista de racionalização da ordem social. Mas não devemos cair nessa armadilha de tomar como natural o que nos é familiar.

Não há nada de natural na possibilidade de os legisladores regularem todos os âmbitos da vida social. Antes da modernidade, amplas parcelas do Direito não podiam ser alteradas por via legislativa e, mesmo dentro das monarquias absolutistas, a maior parte do Direito não tinha natureza legislada. Essa era a situação, por exemplo, do Império Português ao longo do século XVII, quando era regido pelas Ordenações Filipinas, de 1603.

Essa lei estabelecia a organização do Estado português, e em seu livro III, título 64, dispõe que os casos que não fossem por ela regulados deveriam ser julgados com base nas leis, na jurisprudência das cortes ou no Direito consuetudinário local. Na hipótese de essas três fontes serem omissas, o caso deveria ser julgado com base no Direito romano ou, se a questão envolvesse pecado, no Direito canônico. Se o Corpus iuris civilis não determinasse qualquer solução para o caso, deveria ele ser julgado com base nas observações de Acursio e de Bartolo, juristas europeus que escreveram célebres comentários sobre o Direito romano. Por fim, se os juízes não encontrassem em nenhuma dessas fontes subsídios adequados para o julgamento, a questão deveria ser remetida ao próprio rei, para que ele a decidisse.

Portanto, mesmo que os juízes fossem magistrados que agiam em nome dos reis, a sua função se restringiam à aplicação de regras do Direito consuetudinário, romano ou canônico, que não eram passíveis de modificação pelo poder dos monarcas. Antes das grandes codificações do século XIX, a função dos juízes era aplicar o Direito, mas as normas jurídicas não eram tipicamente elementos do Direito legislado, que não 
abrangiam o Direito Civil nem o Direito Comercial. Além disso, muitas das normas sociais provinham de uma regulação autônoma das diversas ordens sociais: famílias (organizadas pelo poder disciplinar do pater), corporações de ofício e comunidades territoriais. Nesse contexto, as próprias Ordenações se limitavam, praticamente, a organizar o Estado, estabelecer as penas e organizar o processo judicial. Fora desses limites, o Direito não adotava uma forma legislativa.

Mesmo na aplicação judicial, a legislação ocupava um papel de menor destaque. O historiador português António Hespanha (1993, p. 13) chegou a afirmar que "em relação à doutrina, a lei não era apenas um fenômeno minoritário, era também um fenômeno subordinado". Isso indica que os juízes gozavam de um grau razoável de independência julgadora, pois a maioria dos casos deveria ser passível de julgamento com base nesse sistema de fontes, que, além de muito complexo, era muito abrangente.

O maior atestado dessa autonomia judicial foi o fato de que, em 1769, o Marquês de Pombal fez editar a Lei da Boa Razão, por meio da qual Portugal regulou as diversas atividades ligadas à aplicação da Justiça, impondo a todos os juízes a observação estrita das leis editadas pela Coroa portuguesa (GILISSEN, 1995, p. 335). A principal finalidade dessa lei era restringir a importância do Direito romano, já que seu conteúdo não era submetido à vontade do monarca e, muitas vezes, funcionava como um limite à sua autoridade. Portanto, a Lei da Boa Razão foi o instrumento utilizado para alterar os quadros estabelecidos pelas Ordenações Filipinas, criando uma subordinação absoluta do Direito romano ao Direito legislado, o que implica uma submissão muito maior dos juízes à vontade do rei.

Esse contexto produzido pelo Estado de expansão do Direito legislado é chamado por António Hespanha de "projeto de redução do pluralismo", que integra o projeto iluminista, configurando uma maneira de suplantar os costumes locais e o Direito romano em troca de uma legislação modernizada, capaz de regular, de modo racional e minucioso, os vários aspectos da vida social. Esse projeto culminou na produção 
dos códigos que revogaram as ordens costumeiras, estabelecendo um Direito único para os Estados liberais.

O fim das monarquias absolutistas em nada diminuiu esse movimento, o qual, inclusive, ganhou força nos Estados liberais em que o Poder Legislativo passou a ser o grande foco de produção normativa. Com isso, a função dos legisladores mudou radicalmente, especialmente no continente europeu: enquanto a função legislativa dos monarcas era bastante restrita, a dos poderes legislativos era elaborar um Direito amplo, que deveria regular toda a vida social.

No períodos clássico e medieval, não havia uma pretensão de que o Direito positivo regulasse todas as situações sociais. Mesmo no início da Idade Moderna, reconhecia-se que o Direito vigente regulava apenas parte da vida das pessoas, e que cabia ao Poder Legislativo criar ou não direitos e obrigações, em função dos interesses sociais envolvidos. Porém, o desenvolvimento dos estudos romanistas permitiu aos iluministas a criação de uma utopia totalizante: a capacidade de extrair dos sistemas de Direito as soluções para todos os conflitos de interesse. Na perspectiva do século XVII, exemplificada pelas Ordenações Filipinas, o Direito era amplo, as fontes eram múltiplas, mas a sua incompletude era reconhecida: os casos não regulados deveriam ser enviados para a decisão autônoma do rei. No entanto, na perspectiva dos iluministas, essa era uma possibilidade vazia, visto que uma análise racional do Direito deveria ser capaz de oferecer solução para todos os casos concretos.

Essa mudança de perspectiva fez com que se ampliassem as fronteiras do próprio Direito positivo, que deixou de ser um fenômeno percebido como seletivo e passou a ser compreendido como universal. Como veio a ser descrito pela teoria jurídica do século XIX, o Direito precisa ser compreendido como um sistema completo, capaz de oferecer solução a todos os conflitos sociais relevantes. É evidente que a pretensão de completude é uma idealização, ainda mais considerando que ela se combina com o projeto iluminista de reduzir o Direito à lei. Essa combinação de legalidade e completude conduziu à elaboração de 
códigos, ou seja, de leis que deveriam ser capazes de suprir a demanda iluminista por um Direito simultaneamente legislado e completo. $E$ tal alteração na estrutura do Direito implicou em uma mudança radical na função judicial: a universalização da jurisdição.

\subsection{Universalização da jurisdição}

$\mathrm{Na}$ esteira das revoluções burguesas, o projeto iluminista de estabelecer um Direito legislado que abrangesse todas as relações sociais levou os próprios legisladores a estabelecerem a vedação do non liquet. Antes disso, somente eram judicializáveis as questões que se enquadravam em alguma das ações existentes. Pedidos que extrapolavam as vias de acesso estabelecidas eram julgados como não líquidos, o que significava que não cabia ao Judiciário resolver a questão. Com a Revolução Francesa e a codificação, estabeleceu-se que os juízes deveriam julgar todos os casos que lhes fossem apresentados, e que a denegação de Justiça seria uma falta grave.

Com isso, o legislador estabeleceu que os juízes deveriam encarar o Direito como um sistema que abrangia todos os pedidos possíveis. Por mais que os códigos apresentassem sistemas abrangentes, isso significava que eles regulavam de forma objetiva todas as relações entre os cidadãos, de tal forma que os juízes receberam uma missão aparentemente impossível: julgar todos os conflitos individuais a partir de um conjunto de regras idealmente considerado como completo, mas realmente lacunar.

Nesse contexto, os juízes se viram forçados a um uso mais intensivo de estratégias hermenêuticas voltadas a oferecer respostas que fossem extraídas da lei, mas que precisavam ultrapassar a literalidade. Ao longo do século XIX, essa necessidade de extrair soluções adequadas de um Direito incompleto fez com que se desenvolvessem argumentos que suplantassem a literalidade, tanto a partir da vontade do legislador quanto a partir de argumentos históricos e sistemáticos.

Esse sistema deu mostras de esgotamento no final do século XIX, quando as modificações sociais ligadas aos processos de 
industrialização e urbanização tornaram o Direito Civil, em grande medida, obsoleto, especialmente para tratar das novas relações de emprego. Naquele momento, os juristas precisaram exercitar ao máximo sua criatividade hermenêutica para buscar, fora do Direito, elementos capazes de influenciar suas decisões. Esse foi o momento das várias escolas de matriz sociológico, que viam o Direito como um instrumento de regulação social que precisava ser adequado às finalidades sociais.

Essa estratégia de abertura hermenêutica do Direito à sociedade foi sendo abandonada no começo do século $X X$, pois o problema que ela enfrentava, gradualmente, deixou de existir: os velhos códigos foram substituídos por uma nova legislação, mais adaptada às realidades sociais. O ordenamento jurídico novecentista não oferecia respostas adequadas às novas relações de emprego, às novas sociedades urbanas e industriais, e à sociedade de consumo nascente. Assim, o século $X X$ assistiu a uma ampliação da participação política, à universalização do voto, à proteção jurídica do emprego e à instituição de regimes gerais de previdência e educação. Esse movimento tornou o Direito muito mais abrangente, afinal, ele passou a abranger áreas novas. Além disso, tornou-se muito mais flexível, pois os direitos sociais eram apresentados, muitas vezes, na forma de princípios abertos, de pautas que precisavam de concretização.

Nesse contexto, houve uma alteração na hermenêutica jurídica. $\mathrm{Na}$ passagem do século XIX para XX, a crise de legitimidade (interpretada como uma espécie de "guerra dos fatos contra o Direito") foi enfrentada a partir de uma tentativa de abertura do Direito para os valores sociais. Ao longo do século $X X$, esses valores sociais foram cristalizados em forma de legislação, o que tornou o Direito muito mais permeável aos próprios valores sociais, especialmente por meio das formulações cada vez mais abertas. Com isso, toda a argumentação que precisava ser metajurídica, toda a necessidade de tornar o Direito justo passou a ser interpretada pelos juristas como a necessidade de conferir efetividade ao próprio ordenamento.

Tal combinação de ampliação da legislação e de universalidade da jurisdição elevou a importância do Poder Judiciário, que se viu 
incumbido de garantir a efetivação dos direitos estabelecidos pela nova legislação. Essa alteração poderia não ter tido efeitos políticos sentidos como relevantes, já que o Judiciário continuava a apreciar conflitos individuais, e não questões de impacto mais geral. Porém, a combinação desses elementos com a universalização do controle de constitucionalidade multiplicou a relevância política do Poder Judiciário.

\subsection{Controle de constitucionalidade e direitos sociais}

Enquanto aplicadores das leis, os juízes exercem uma importante função interpretativa, mas o resultado de sua atividade se aplica, normalmente, a casos reduzidos: tanto eram poucos os conflitos sociais levados ao Judiciário, como as repercussões eram pequenas, na medida em que os magistrados julgavam conflitos entre particulares. Essa situação mudou bastante com a consolidação, no século XIX, da possibilidade de o Judiciário controlar a legalidade dos atos do Poder Executivo. Esse controle judicial da administração pública foi compreendido como uma efetivação do Estado de Direito, no qual todas as autoridades são submetidas à lei. Nos Estados constitucionais, o princípio de que "the king can do no wrong" é substituído por um discurso de direitos oponíveis ao próprio Estado, inclusive por via judicial.

Esse movimento se radicalizou quando os juízes passaram a controlar a atividade estatal por meio de uma interpretação direta do texto constitucional, o que permitiu que eles passassem a julgar a constitucionalidade dos atos legislativos e executivos. Não é demasiado lembrar que o controle de constitucionalidade foi inventado no caso Marbury v. Madison (5 US 137), para resolver uma questão sobre a validade da nomeação de juízes pelo presidente dos EUA, que é um problema mais executivo que legislativo.

O procedimento utilizado não foi inovador, pois avaliar a compatibilidade entre uma norma superior e uma inferior sempre fez parte do papel dos magistrados judiciais. Tais julgamentos sempre tiveram relevância tanto para as partes envolvidas quanto para aqueles que utilizavam esses precedentes para o julgamento de casos futuros. 
Porém, uma vez que o Judiciário passou a avaliar a compatibilidade entre as leis e a constituição, ele passou a poder excluir do ordenamento uma série de atos legislativos, o que fez com que essas decisões tivessem um impacto geral na vida das pessoas.

Esse controle judicial da constitucionalidade das leis era desenvolvimento previsível da constitucionalização, tanto que havia sido intuído pelos próprios federalistas (HAMILTON, MADISON; JAY, 2001, p. 352). Apesar disso, tal intervenção judicial nos atos legislativos foi percebida por muitos, desde o início, como uma espécie de invasão da esfera do Poder Judiciário. Em contraposição, o próprio Judiciário defende, desde o caso Marbury v. Madison, que o desempenho dessa função era a única forma de conferir efetividade às próprias normas constitucionais.

A consolidação do judicial review, bem como a criação do modelo europeu de Cortes Constitucionais, ampliou bastante a função política do Judiciário. Mas essa mudança poderia ter resultados restritos, caso não fosse uma alteração na própria estrutura das constituições, que passaram a ter um caráter cada vez mais principiológico. Enquanto as constituições eram mais restritas, menos programáticas, menos repletas de princípios, a atuação judicial poderia ser mais contida, já que o próprio texto constitucional oferecia parâmetros formais e estruturais, menos do que orientações de conteúdo. Porém, com a ampliação gradual das declarações de direitos, chegamos ao ponto em que se exigia do Judiciário uma interpretação constitucional e se oferecia a ele uma constituição muito aberta.

Enquanto o século XIX desenvolveu formas de incorporar critérios metajurídicos à interpretação do Direito, o século $X X$ introduziu esses critérios no próprio Direito constitucional. Assim, a necessidade de tornar o Direito justo passou a ser interpretada pelos juristas como a necessidade de conferir efetividade a uma constituição que consagrava os princípios de igualdade e justiça social. Essa nova estrutura do Direito estimulou uma nova postura nos juízes: dar aplicabilidade à constituição, extrair dela todas as suas dimensões, levá-la aos seus 
limites e exigir dos legisladores uma compatibilidade máxima com as normas constitucionais.

Mesmo em países onde o texto permaneceu inalterado, houve uma mudança relevante na própria compreensão dos direitos fundamentais de primeira geração, que passaram a ser entendidos como pautas valorativas mais densas. Em especial, a leitura formal da igualdade e da liberdade, típicas do liberalismo do século XIX, foi substituída por leituras mais substanciais. O caso mais emblemático foi a substituição, nos EUA, da doutrina do "separados, mas iguais" pela afirmação da necessidade de um tratamento efetivamente igualitário entre brancos e negros.

Assim, as constituições passaram a ter uma estrutura valorativa mais aberta, cuja aplicação em casos práticos depende de uma série de opções ideológicas e valorativas por parte dos intérpretes. Esse desafio colocado à jurisdição exigiu o estabelecimento de uma série de novas estratégias interpretativas, e alçou o Judiciário à posição de influenciar decisivamente na regulação de temas com repercussões políticas de primeira grandeza. O ativismo judicial, que antes tinha grande relevância para as partes e reflexos gerais apenas por fixar precedentes, passou a ter capacidade de intervir na própria configuração do Direito positivo, especialmente por meio da anulação de normas consideradas violadoras dos direitos fundamentais.

\section{Conclusão}

Que resultados podem advir dessa combinação de (1) um Direito legislado muito abrangente, (2) uma universalidade da jurisdição e (3) uma estrutura constitucional aberta?

Uma das alterações mais evidentes ocorreu no próprio discurso político, que, cada vez mais, apresenta-se como um discurso jurídico de efetivação de direitos. No Brasil, especialmente depois da publicação da Constituição de 1988, o discurso ligado aos direitos sociais tende a não se apresentar como uma luta pela construção ou conquista de direitos, 
mas como um esforço para a efetivação de direitos já garantidos pelos textos constitucionais e tratados internacionais. No século XIX, o discurso da justiça social envolvia uma espécie de revolta contra um Direito incompleto e ultrapassado, uma revolta dos fatos contra os códigos. No século XX, a ampliação dos direitos humanos e fundamentais permitiu que vários movimentos sociais caracterizassem seu engajamento como uma busca pela concretização de direitos sociais que já faziam parte do próprio ordenamento jurídico.

Essa foi uma mudança estrutural na própria esfera política. A resposta legislativa às demandas sociais tem sido feita, cada vez mais, por meio de textos normativos de caráter principiológico, especialmente em sede constitucional, com o reconhecimento de uma série de direitos que são pouco mais do que promessas abstratas. Como acentuou Hespanha (1993, p. 23), enquanto as leis do século XIX eram instrumentos para a explicitação de direitos e deveres, as leis do séc. XX cumprem não apenas uma função reguladora, mas uma função simbólica: "Muito frequentemente a lei é utilizada para enunciar de forma solene e propagandística as intenções do poder; um pouco independentemente de tais intenções serem realmente praticáveis ou de o poder tencionar levá-las à prática”.

Frente a esse uso da lei para consagrar princípios abstratos e não regulações concretas, qual deveria ser a postura dos juízes? Uma possibilidade seria a de reconhecer que muitas normas jurídicas têm caráter programático e de que, nessa medida, elas não conferem aos cidadãos direitos que possam ser exigidos, apenas pretensões políticas genéricas que precisam ser concretizadas por uma ação legislativa antes de serem passíveis de efetivação judicial. Essa não seria uma postura inovadora, pois representa apenas conferir a princípios do Direito positivo o mesmo tratamento jurídico que, durante séculos, foi conferido aos princípios do Direito natural, que serviam como diretrizes para o legislador, mas não eram diretamente aplicáveis pelos magistrados. Essa estratégia foi muito utilizada por poderes judiciários pouco propensos a assumir uma postura ativa na garantia das leis, porém, foi percebida como uma forma de esvaziar a importância da 
própria legislação, especialmente dos princípios constitucionais, que ficaram reduzidos a uma promessa vazia.

Nesse contexto, os magistrados são levados a enfrentar um dilema político: ou eles abdicam de sua função de aplicadores (reconhecendo o caráter meramente programático dos princípios constitucionais) ou realizam interpretações que implicam a adoção de posicionamentos com alta densidade ideológica. Não há como interpretar um Direito com textura aberta sem o recurso a valores sociais que confiram densidade aos conceitos abertos da legislação atual: devido processo legal, repercussão geral, igualdade e razoabilidade. Além disso, os próprios constituintes determinaram, no $\S 1^{\circ}$ do art. $5^{\circ}$, que "as normas definidoras dos direitos e garantias fundamentais têm aplicação imediata”. Quando a aplicação do próprio Direito exige a adoção de uma postura ativa e a Constituição chega a vedar explicitamente a redução dos direitos fundamentais a diretrizes programáticas, não deve causar espanto o fato de que tem sido crescente o grau de ativismo entre os magistrados brasileiros desde 1988. Nessa medida, um incremento no ativismo judicial como parte desse processo em que as conquistas políticas se convertem em direitos, cuja efetividade depende de uma postura ativa das cortes judiciais.

Mas será que esse processo de protagonismo judicial não nos levou demasiadamente longe, convertendo-se em uma tese de supremacia judicial que subverte o sistema liberal de checks and balances? Será que essa carga interpretativa exigida da atividade judicial não terminou por anular a vantagem da divisão de poderes, que é justamente para impossibilitar que qualquer um dos poderes concentre para si a autoridade soberana, tendo a última palavra em todos os assuntos? Uma análise do discurso contemporâneo do STF indica que tal barreira está sendo ultrapassada, ou ao menos que estamos caminhando perigosamente nesse sentido. Sintomático é o fato de o STF ter chegado a afirmar que ele próprio tem "a magna prerrogativa de decidir, em última análise, sobre a própria substância do poder" (STF, MS n. 26.603).

A RCL n. 4.335, ainda em julgamento no STF, propiciou reações consistentes, como o questionamento direto de Lenio Streck, Marcelo 
Cattoni e Martonio Lima (2007) à defesa pelo Supremo de sua legitimidade para impor "mutações constitucionais": "Afinal, cabe ao STF 'corrigir' a Constituição? A resposta é não. Isso faria dele um poder constituinte permanente e ilegítimo". Reações também indignadas têm acompanhado a recente decisão do STF de conferir a si próprio o direito de cassar mandatos de parlamentares (BENVINDO, 2012).

A inexistência de mecanismos de proteção específica contra a afirmação institucional de uma soberania hermenêutica do STF tem inspirado reações legislativas, como a proposta de controle das decisões do STF pelo Congresso Nacional, contida na PEC n. 33/2011, em que se propõe uma elevação do quórum para a declaração de inconstitucionalidade, a vedação de suspensão liminar da validade de emendas à constituição e a instituição de um controle legislativo de decisões do Supremo. Embora a constitucionalidade dessa medida seja questionável, inclusive porque ela teria o curioso efeito de afastar a si própria do controle jurisdicional, ela levanta um saudável espaço de discussão sobre os processos políticos de tomada de decisão que desejamos.

A modelagem das instituições do Estado, inclusive do papel de cada uma delas na formulação e interpretação dos preceitos constitucionais que regulam o exercício do poder, é um dos elementos centrais da Política. Precisamos avaliar os processos de tomada de decisão existentes e escolher os tipos de procedimento que consideramos mais adequados a uma democracia. Isso ainda é o papel da Política: determinar em que medida a nossa sociedade reproduzirá os padrões vigentes ou implementará mudanças em sua organização. Esse foco nos processos decisórios e nas estruturas institucionais não é o mais típico dos políticos nem dos juristas, que normalmente avaliam a adequação das decisões judiciais a partir do seu resultado, e não dos argumentos ou processos que levaram a ela.

A decisão do STF sobre a decisão homoafetiva ou sobre a ficha limpa foi correta? O problema é o resultado, e não o fundamento. Isso é especialmente grave no Brasil porque, em nosso sistema, o que 
faz coisa julgada não é o argumento, mas o dispositivo das decisões judiciais. Adotar a justiça do resultado como critério decisório faz com que possamos reforçar certas posturas judiciais indevidas, especialmente a falta de uma fundamentação consistente (CARVALHO, 2012).

Por isso, creio que devemos tomar cuidado com o tipo de argumentação que consideramos aceitável por parte do Judiciário, especialmente com o nível de ativismo que está envolvido na noção de concretização das normas constitucionais. A decisão judicial dessas questões faz com que as opções políticas consagradas pelo Judiciário se tornem blindadas ao debate político democrático. Uma lei pode ser mudada a partir de um acordo entre as forças políticas. O texto da constituição, também. Uma interpretação judicial, contudo, é pouco sujeita a alteração, pois depende da mudança de opinião dos julgadores ou de composição dos Tribunais.

Quando o Judiciário atua interpretando as leis, o Legislativo sempre pode alterar os sentidos jurídicos produzidos mediante a edição de uma nova lei. Assim, por mais que a atuação judicial fixe sentidos, a atuação dos outros atores políticos pode regular de modo diverso a situação. Porém, uma vez que o Judiciário julga a partir da própria constituição, o assunto tratado é retirado do campo daquilo que pode ser estipulado mediante composições de interesse. A judicialização da Política garante a coerência e a sistematicidade do próprio ordenamento, na medida em que impede que várias questões sejam reguladas em desconformidade com os princípios básicos do Direito, que são redesenhados pelas próprias autoridades judiciais. Todavia, os imperativos de sistematicidade podem colidir com as concepções dominantes de justiça.

Como evidenciou Vallinder (1994, p. 92), judicial e legislativo indicam dois modelos de tomada de decisão política: um deles fundado na determinação de uma "solução correta" e outro fundado na busca de uma "solução politicamente aceitável". Mesmo que admitamos que a interpretação correta da norma não passa de um princípio regulador da retórica judicial, a adoção desse critério de correção faz com que o procedimento judicial tenda a produzir decisões coerentes entre si, mais 
do que decisões desejadas pelas partes em conflito. Nesse sentido, os interesses efetivos da sociedade (ainda que esse também seja um conceito idealizado) não podem ser incluídos no debate, dado que o critério de correção é pautado por outras categorias.

Encarar todos os conflitos de interesse a partir de um discurso de direitos significa reduzir os problemas políticos a questões hermenêuticas, e essa estratégia é insuficiente para dar conta da complexidade social, pois impede que questões delicadas sejam resolvidas a partir da composição efetiva dos interesses sociais em jogo. Em certa medida, o Judiciário sempre pode reafirmar a velha máxima de que fiat justicia pereat mundus, já que não existem elementos discursivos no Direito capazes de estabelecer uma pesagem adequada dos conflitos de direitos. Esse perigo tem sido enfrentado com o desenvolvimento de argumentos judiciais que permitem a limitação do próprio Direito aplicado.

Existe, por exemplo, uma utilização cada vez mais ampla de estratégias de balanceamento permitindo a acomodação de direitos que, teoricamente, não poderiam ser acomodados, o que desloca para o próprio Judiciário o estabelecimento das composições obrigatórias de interesses. Além disso, a crescente modulação dos efeitos das sentenças permite ao Judiciário estabelecer o direito futuro sem alterar o passado, função que normalmente era exercida pelos legisladores. E cada vez mais se afirma na jurisprudência do STF a possibilidade de fazer uso de estratégias manifestamente legislativas, como o reconhecimento de mutações constitucionais ou edição de sentenças aditivas. Tudo isso indica que a judicialização da Política implica um movimento correlato de politização do Judiciário, na medida em que a solução das questões normativas está acoplada ao desenvolvimento de atividades e discursos que não se apresentam como identificação de uma solução correta, mas como formas de adequar a decisão aos valores e às necessidades sociais.

Essas estratégias são indispensáveis para evitar que o discurso de direitos e os imperativos de sistematicidade terminem conduzindo os magistrados a tomar decisões que serão percebidas como absurdas. 
Todavia, quando o Judiciário tenta "extrair" da constituição o limite dos seus significados, ele termina por fixar certas escolhas como intangíveis ao outros poderes, e essas opções se tornam demasiadamente rígidas porque "judges are not very much inclined to revise judicial review and to adapt it to a changing political and social situation" (LANDFRIED, 1994, p. 122).

Quando tratamos da efetivação de princípios constitucionais bem assentados na nossa cultura, como é o caso da isonomia, isso pode conduzir a uma proteção mais efetiva dos direitos fundamentais. Porém, a nossa realidade é a de que várias decisões são tomadas muito além desses limites, como ocorreu, por exemplo, na definição judicial das regras sobre fidelidade partidária, que não impõem uma garantia de direitos humanos, mas uma determinada estrutura de organização política (ADI n. 3.999 e ADI n. 4.086). E chegamos ao limite quando o STF começa a redefinir os limites de validade das suas decisões, que geram o que se tem chamado de uma Supremocracia: uma supremacia das decisões do STF sobre quaisquer outras decisões, inclusive legislativas. E, como acentuou Louis Fisher (1988, p. 278), a crença numa supremacia judicial "sets up excpetations that invite disappointment if not disaster".

Por isso, embora não pareça conveniente limitar em abstrato o exercício do controle de constitucionalidade, é possível estabelecer procedimentos mais exigentes em termos de justificação. Mesmo que a decisão judicial de questões políticas não seja em si um mal, parece-me um equívoco tomar decisões políticas sem uma avaliação cuidadosa das suas repercussões, sem o aconselhamento de especialistas e sem ouvir os interessados, como se fosse possível definir as soluções adequadas à sociedade a partir de uma aplicação técnica do Direito.

O problema não é propriamente a judicialização da Política, mas o modo como ela se tem processado. Portanto, o nosso desafio não é o de limitar a participação do Judiciário nos processos estatais de tomada de decisão, mas elaborar critérios de intervenção capazes de tornar essa participação proveitosa a uma sociedade democrática, o que exige ao menos o desenvolvimento de processos que evitem a mistificação 
de que essa atuação se trata de uma revelação de sentidos implícitos, e não de uma criação de sentidos adequados, demonstrando que há, nela, mais fronesis do que técnica, mais julgamentos de equidade do que juízos de subsunção. Assim, admitir claramente o caráter político da atuação judicial é o primeiro passo para que ela possa se tornar politicamente útil e democraticamente legítima, especialmente porque Fischer (1988, p. 38) parece ter razão ao afirmar que "ironically, judges are more likely to confine their lawmaking if they are conscious of their role and the need to transcend bias and prejudice".

\section{Referências}

ARBIB, M. From monkey-like action recognition to human language: an evolutionary framework for neurolinguistics. Behavioral and Brain Sciences, v. 28, n. 2, p. 131-132, abr. 2005. Disponível em: <http://goo. gl/O6Jaa>. Acesso em: 13 out. 2012.

BARROSO, Luis R. Constituição, democracia e supremacia judicial: direito e política no Brasil contemporâneo. Revista Jurídica da Presidência, Brasília, DF, v. 12, n. 96, p. 3-41, fev./maio 2010.

BENVINDO, Juliano Z. STF, separação de poderes e cassação de mandatos. Constitucionalismo e democracia. Disponível em: <http:// goo.gl/uYHO2>. Acesso em: 10 fev. 1013.

CARVALHO, Alexandre D. A hermenêutica constitucional entre a estabilidade e a dinâmica: elementos para uma compreensão do conceito de mutação constitucional. In: ENCONTRO NACIONAL DO CONPEDI, 20., 2011, Florianópolis. Anais... Florianópolis: Fundação Boiteux, 2011.

COSTA, Alexandre A. Direito e método: diálogos entre a hermenêutica filosófica e a hermenêutica jurídica. Tese (Doutorado em Direito)Universidade de Brasília, 2008. Disponível em: <http://www.arcos.org. br/livros/hermeneutica-juridica/>. Acesso em: 18/ jul. 2011.

DAMASIO, Antonio R. Looking for Spinoza. Boston: Houghton Mifflin Harcourt, 2003. 
DWORKIN, Ronald. 0 império do direito. São Paulo: Martins Fontes, 2003.

EHRLICH, Eugen. Fundamentos da sociologia do direito. Brasília, DF: UnB, 1986.

FISHER, Louis. Constitutional dialogues: interpretation as political process. Princeton: Princeton University Press, 1988.

FREEMAN, Samuel.Democraciaecontrolejurídicodaconstitucionalidade. Lua Nova, São Paulo, n. 32, p.181-199, 1994. Disponível em: <http:// goo.gl/pm6Hm>. Acesso em: 10 fev. 2013.

GÉNY, François. Méthode d'ínterprétation et sources en droit privé positif: essai critique. 2. ed. Paris: Librairie Générale de Droit \& de Jurisprudence, 1954.

GILISSEN, John. Introdução histórica ao direito. 2. ed. Lisboa: Calouste Gulbenkian, 1995.

HAMILTON, Alexander; MADISON, James; JAY, John. The federalist papers. The Pensilvania State University, 2001. Disponível em: <http:// goo.gl/tdXcN>. Acesso em: 18 jul. 2011.

HART, Herbert L. A. O conceito de direito. 2. ed. Lisboa: Calouste Gulbenkian, 1994.

HESPANHA, António M. Justiça e litigiosidade: história e prospectiva. Lisboa: Calouste Gulbenkian, 1993.

HOBBES, Thomas. Leviatã ou matéria, forma e poder de um Estado eclesiástico e civil. São Paulo: Nova Cultural, 1997.

HODGSON, G. M.; KNUDSEN, T. Darwin's conjecture (e-book.). Chicago: University Of Chicago Press, 2010.

KELSEN, Hans. Teoria pura do direito. São Paulo: Martins Fontes, 2003.

LANDFRIED, Christine. The judicialization of politics in germany. International Political Science Review, v. 15, n. 2, p.113-124, abr. 1994. 
LARENZ, Karl. Metodologia da ciência do direito. 2. ed. Lisboa: Calouste Gulbenkian, 1982.

MACIEL, Débora A.; KOERNER, Andrei. Sentidos da judicialização da política: duas análises. Lua Nova, São Paulo, n. 57, p. 113-133, 2002.

MENDES, Gilmar F. O papel do Senado Federal no controle de constitucionalidade: um caso clássico de mutação constitucional. Revista de Informação Legislativa, Brasília, DF, v. 41, n. 162, p. 149168, abr./jun. 2004.

NEVES, Marcelo. O abuso de princípios no Supremo Tribunal Federal. Revista Consultor Jurídico, São Paulo, 2012. Disponível em: <http:// goo.gl/Gw66o>. Acesso em: 20 jan. 2013.

NIETZSCHE, Friedrich. O crepúsculo dos ídolos. São Paulo: Companhia das Letras, 2006.

PERELMAN, Chaïm. Lógica jurídica: nova retórica. São Paulo: Martins Fontes, 1998.

SARMENTO, Daniel. O neoconstitucionalismo no Brasil: riscos e possibilidades. Revista Brasileira de Estudos Constitucionais, Belo Horizonte, v. 3, n. 9, p. 95-133, jan. 2009.

SILVA, Alfredo C. G. da. Revisão e controle do poder legislativo das decisões da Suprema Corte. Portal Jurídico Investidura, Florianópolis, 4 jun. 2010. Disponível em: <www.investidura.com.br/biblioteca-juridica/ artigos/judiciario/162959>. Acesso em: 9 fev. 2013.

STRECK, Lenio; CATTONI DE OLIVEIRA, Marcelo; LIMA, Martonio. Mutações na corte: a nova perspectiva do STF sobre controle difuso. Consultor Jurídico, v. 1, p. 58991, 2007. Disponível em: <http://goo.gl/ XnUVZ>. Acesso em: 20 fev. 2013.

TAMANAHA, Brian. Realistic socio-legal theory: pragmatism and a social theory of law. New York: Oxford University Press, 1997.

VALLINDER, Torbjörn. The judicialization of politics: a world-wide phenomenon: introduction. International Political Science Review, v. 15, n. 2, p. 91-99, Apr. 1994. 
YAMAMOTO, S.; HUMLE, T.; TANAKA, M. Basis for cumulative cultural evolution in chimpanzees: social learning of a more efficient tool-use technique. PLoS ONE, v. 8, n. 1, 2013. Disponível em: <http://goo.gl/ BewRL>. Acesso em: 20 fev. 2013.

Recebido em: 27/03/12

Aprovado em: 14/02/13 